\title{
Morpho-Physiological Characterization of Winter Wheat "Buster" Population during the Vegetative Stage under Heat Stress
}

\author{
Pratishtha Poudel, Vijaya Gopal Kakani*, Phillip D. Alderman, Brett F. Carver \\ Department of Plant and Soil Sciences, Oklahoma State University, Stillwater, OK, USA \\ Email: *v.g.kakani@okstate.edu
}

How to cite this paper: Poudel, P., Kakani, V.G., Alderman, P.D. and Carver, B.F. (2020) Morpho-Physiological Characterization of Winter Wheat "Buster" Population during the Vegetative Stage under Heat Stress. American Journal of Plant Sciences, 11, 1276-1295.

https://doi.org/10.4236/ajps.2020.118091

Received: February 14, 2020

Accepted: August 18, 2020

Published: August 21, 2020

Copyright $\odot 2020$ by author(s) and Scientific Research Publishing Inc. This work is licensed under the Creative Commons Attribution International License (CC BY 4.0).

http://creativecommons.org/licenses/by/4.0/

(c) (i) Open Access

\begin{abstract}
Phenotypic assessment of breeding population is important to identify robust lines for incorporating into future breeding programs. The objective of this study was to identify potential lines from a wheat (Triticum aestivum L.) population, based on their morpho-physiological traits, for improved heat tolerance. A subset of 100 lines of the double haploid (DH) population named "Buster", developed from two successful Oklahoma wheat varieties (Billings and Duster), was used in the study. Two experiments were conducted one in a greenhouse and the other in growth chambers. Data on plant height, tiller number, leaf number, and photosynthetic pigments were collected from the greenhouse; whereas the data on physiological parameters (leaf net photosynthesis $(\mathrm{Pn})$, transpiration $(\mathrm{T})$, stomatal conductance $\left(\mathrm{g}_{\mathrm{s}}\right)$, intercellular carbon dioxide concentration $\left(\mathrm{C}_{\mathrm{i}}\right)$, electron transport rate (ETR), Photosystem II efficiency $\left(\mathrm{Fv}^{\prime} / \mathrm{Fm}\right)$ and instantaneous water use efficiency (IWUE)) were collected from the growth chambers. Buster lines were significantly $(P<$ $0.05)$ different both morphologically and physiologically. A wide range of observations among genotypes for different morphological and physiological characteristics was found. For example, the Chlorophyll A:B ratio ranged from 1.8 to 4.3 , average plant height ranged from 8.4 to $13.3 \mathrm{~cm}$, and the net photosynthesis under heat stress ranged from 11.29 to $25.28 \mu \mathrm{mol} \mathrm{CO}_{2}$ $\mathrm{m}^{-2} \cdot \mathrm{s}^{-1}$. The differences in leaf physiological parameters were more discernible under heat stress. This study provides a piece of baseline information on morpho-physiological characteristics of Buster lines, and identified lines can be used in future breeding programs for incorporating heat stress tolerance.
\end{abstract}

\section{Keywords}

Wheat, Breeding, Buster, Heat Stress, Morphological, Photosynthesis, Physiological 


\section{Introduction}

The global temperature increase is projected to range, depending on the location, between $1.5^{\circ} \mathrm{C}$ and $11^{\circ} \mathrm{C}$ by the year 2100 [1]. The high temperature at the beginning of spring season, coinciding with anthesis and grain-filling stages of the wheat crop, substantially reduces grain number and size [2]. This leads to a decrease in overall wheat productivity. Several studies have screened genotypes for heat tolerance [3] [4] [5]. However, most of these studies have considered either the whole plant life cycle or the post-anthesis period of crop growth. Hence, screening plants for the heat tolerance traits at early plant growth stages can help shorten the time period of the selection process, thus shortening breeding cycles and increasing genetic gain at a reduced time and cost. In this study, we screen 100 genotypes from a double haploid population for heat tolerance at the vegetative growth stage based on morpho-physiological traits.

Morpho-physiological improvements are one of the reasons behind increased productivity in winter wheat [6]. Selection of genotypes for higher yield based on their morphological characteristics including plant height in wheat [7], tiller number in wheat [8] and leaf area [9] in several horticultural crops such as cherries, grapes, and strawberries have been a successful approach for crops improvement. Similarly, morphological attributes are also taken into account while developing a tolerant variety for abiotic stresses such as heat and drought in wheat [10] [11] [12]. The number of effective tillers (fertile tillers) is an important yield attribute in wheat [13], and a source of difference between wheat genotypes [14]. Likewise, short plant height is an ideotype for wheat and one of the main reasons for the increase in wheat yields in the last five decades [6] [15]. Another important trait used for genotypic selection is the leaf area as the per unit area leaf traits may not represent the actual differences and produce misleading results [9] [16]. A negative correlation was recorded between leaf area and photosynthesis per unit leaf area as indicated by correlation analysis [16] [17]. Balota et al. [11] found that the drought-tolerant wheat varieties have significantly smaller leaves under both irrigated and drought conditions as compared to drought susceptible varieties. We take into account plant height, number of tillers, leaf area, and leaf number in order to make accurate inferences on the population studied.

In addition to the morphological traits, plant physiological processes have a deterministic effect on crop yield. Photosynthesis is one of the major factors influencing crop growth, biomass, and yield [18] [19] [20]. Plants are able to survive the climate extremes because of plasticity and resiliency of photosynthesis [21]. Therefore, understanding the response of photosynthesis to the changing environment is necessary to correctly assess the changes in plant productivity [22]. Xue et al. [23] found a positive correlation between leaf photosynthetic rates and grain yield in a few studies but no relation was observed in several studies identified in the review. According to Long et al. (2006) [24], leaf photosynthetic rates correlated poorly with yield in the past, but several recent studies 
are showing an increase in yield with an increase in photosynthetic rates.

In addition to exploring differences in photosynthetic rates between the genotypes, our study also pays attention to the stomatal conductance since it affects all gas exchange processes. Stomatal conductance is the rate of $\mathrm{CO}_{2}$ moving in and water vapor moving out of the stomatal apertures in leaf. The rates of diffusion of $\mathrm{CO}_{2}$ into leaf for photosynthesis and water vapor out of the leaf for transpiration are controlled by the stomatal aperture openings [25]. Variation in stomatal conductance among genotypes can be utilized in the selection of wheat lines for improved adaptation in a wide range of growing conditions [3]. Higher stomatal conductance is associated with an increase in grain yield in wheat [26]. The three processes that light can undergo in a leaf after the chlorophyll molecules receive light are photosynthesis, heat dissipation, and chlorophyll fluorescence. This chlorophyll fluorescence is the process of dissipating excess light as re-emission by chlorophyll A after fulfilling the photosynthetic demands [27]. These three processes always counterbalance each other's efficiency increasing one of them while the others decrease [28]. Therefore, chlorophyll fluorescence ultimately reflects the photosynthetic activities of a plant in a complex manner [29]. Chlorophyll fluorescence measurement is one of the well-established techniques to evaluate the integrity of photosynthetic apparatus for stress detection in plants [30] [31].

During photosynthesis, chlorophyll absorbs photon for $\mathrm{CO}_{2}$ fixation [32]. If excess photons are absorbed by chlorophyll (more than a leaf can use for fixing $\mathrm{CO}_{2}$ ), then ROS are formed which cause photo-oxidative damage to the leaves [33] [34]. There are antioxidant compounds present in the leaves that scavenge the ROS and protect the photosynthetic apparatus (Photosystem-I + photosystem-II) [35] [36]. A category of such antioxidant compounds is phenolics. Phenolic compounds scavenge the ROS produced during light reactions in photosynthesis under moderate and high irradiance [32]. The concentration of phenolic compounds correlates positively to antioxidant activities [37]. [38] showed that phenolic compounds are reliable indicators for differences in genotypes in Triticale spp., especially in water deficit conditions where resistant genotypes had higher phenolic content compared to susceptible genotypes. Likewise, carotenoids are one of the indispensable components of photosynthetic mechanism in plants and several studies have demonstrated their importance [39] [40] [41]. Carotenoids play a major role in photosynthesis by harvesting light to extend the spectral range and protecting chlorophyll from photo-oxidative damage [39] [42] [43]. Most of the carotenoids are present in the thylakoid membrane of leaves, which is the site for light reactions of photosynthesis. Carotenoids improve electron transfer and light-harvesting efficiency of plants to stabilize the photosynthetic apparatus and protect it from photo-destruction [41].

This study aims to identify lines with desirable morpho-physiological traits for heat stress tolerance from a double haploid population called "Buster". We hypothesize that double haploid lines of "Buster" population will enable us to amplify the responses to heat stress. 


\section{Materials and Methods}

This study was conducted at Oklahoma State University in Stillwater, OK, USA. Two experiments were conducted, one in a greenhouse (Feb.-May, 2015) and in growth chambers. A subset of a hundred double haploid (DH) lines from a total of 256 Buster DH lines were used for both the experiments.

\section{Buster Population}

This study utilized the plant materials from a double haploid (DH) population developed by the OSU WIT. This population resulted from 32 F1's obtained by crossing two popular wheat varieties "Duster" and "Billings". From an ancestral perspective, "Duster" and "Billings" probably account for the largest segment of the elite germplasm currently flowing through the OSU WIT variety development program. These two parent lines demonstrate high yield potential with impressive disease resistance and end-use quality performance. However, they reach their yield in different and complementary ways with "Duster" having high kernel number and drought resistance, while "Billings" has large kernel size and is susceptible to drought. In addition, "Duster" and "Billings" show wide pattern differences in reproductive development, yet all known genes for reproductive development were identical between them. A population developed combing these varieties would have extremely high potential value to variety development. The OSU WIT envisions that a DH population would lead to trait discoveries, marker discoveries, knowledge of inheritance, and reduce the breeding time that would have far-reaching impact in further manipulating the pipeline (B. Carver, personal communication).

To this effect, $36 \mathrm{~F} 1$ seeds from the single cross Duster/Billings (OK10x994) were provided to Heartland Plant Innovations (HPI, Manhattan, KS) on 10/26/10, with the expectation to produce 300 haploids (DHs). Colchicine treatment was used to develop the DHs. At HPI, the D0 and D1 plant generations were reared and D2 seed was provided to WIT at OSU in 2012. A total of 278 DHs were on sufficient supply to plant back in non-replicated single-row observation plots in 2012-2013 at Stillwater. About 271 DHs were then advanced for further evaluation in 2013-2014. The 271 lines were arbitrarily assigned to 6 sets of 42 lines each, plus one overflow set of 19 DHs, to evaluate in replicated field plots in 2014, 2015, and 2016 at Stillwater. Sets were created to reduce block size in the field, and the two parents were included in each set as a common check. Seed yield and seed of $256 \mathrm{DH}$ lines including the parental varieties were available from the 2013-2014 season. The Billings/Duster DH population will be referred to as Buster population (B. Carver, personal communication).

The 100 Buster lines from the total of 256 were selected from a yield trial conducted during the 2013-2014 growing season in Stillwater, OK. This was an extreme drought year with a $270 \%$ yield difference between the low and high yielding lines. Each of the 6 sub-group (described earlier) was divided into high, average and low yield based on the mean yield \pm 1 standard deviation. From each 
yield group, five lines were selected resulting in 15 lines for each subgroup. A few additional lines with extreme yield values along with parents were selected to create the set of 100 Buster lines for this research.

\section{Greenhouse conditions}

The greenhouse study was conducted without imposing any artificial stress. Five seeds of each line were sown in PVC pots $50 \mathrm{~cm}$ deep and $15 \mathrm{~cm}$ in diameter. There were two replications i.e. two pots per genotype. Pure sand was used as a rooting medium to obtain optimum control of water and nutrient supply to roots. An automatic drip irrigation system was used to supply $0.3 \mathrm{~L}$ of Hoagland's nutrient solution to the plants each time, four times a day at 8:00 AM, 12:00 PM, 4:00 PM and 8:00 PM. In this study, data on leaf morphology (length, width, and area), plant developmental changes (plant height, tiller number, and leaf number) and pigment concentrations (chlorophyll A, chlorophyll B, carotenoids and phenolic content) were collected.

Photosynthetic pigments

Chlorophyll A, chlorophyll B, and carotenoids were extracted using dimethyl sulfoxide (DMSO). Five leaf discs, $1 \mathrm{~cm}^{2}$ each, were punched from five randomly selected leaves from each pot. The leaf discs were stored in $5 \mathrm{ml}$ of DMSO for 24 hours in the dark. The concentrations of the pigments were calculated from absorbance values obtained with a spectrophotometer (Genesys 10 Bio Spectrophotometer, Thermo Scientific) at $664 \mathrm{~nm}, 648 \mathrm{~nm}$ and $470 \mathrm{~nm}$ for chlorophyll A, chlorophyll B, and carotenoids respectively using equations by [44]:

$$
\begin{gathered}
\text { Chlorophyll } \mathrm{A}_{c}=12.25 A_{664 \mathrm{~nm}}-2.79 A_{648 \mathrm{~nm}}, \\
\text { Chlorophyll } \mathrm{B}_{c}=21.50 A_{648 \mathrm{~nm}}-5.10 A_{664 \mathrm{~nm}}, \\
\text { Carotenoids }_{c}=\left(1000 A_{470 \mathrm{~nm}}-1.82 \mathrm{chl} a_{c}-85.02 \mathrm{chl} b_{c}\right) / 198
\end{gathered}
$$

where,

$$
\begin{aligned}
& A=\text { absorbance at respective wavelengths; } \\
& c=\text { pigment concentration }(\mu \mathrm{g} / \mathrm{mL} \text { of extract }) .
\end{aligned}
$$

To determine phenolic compounds concentration, another set of five-leaf discs, $1 \mathrm{~cm}^{2}$ each was punched from the same leaves. The leaf discs were placed in the extractant solution for 24 hours at room temperature. The solution used for the extraction of phenolic compounds was composed of methanol, water, and hydrochloric acid in the ratio of 79:20:1.

Absorbance values were obtained at $330 \mathrm{~nm}$ for phenolic compounds and the concentration was calculated as given by [45]:

$$
C=16.05 * A
$$

where, $C=$ concentration of phenolic compounds $(\mu \mathrm{g} / \mathrm{mL}$ of extract), $A=\mathrm{ab}$ sorbance at $330 \mathrm{~nm}$.

\section{Leaf area}

Three leaves were randomly selected per pot for leaf morphological data measurements after 75 days after sowing (DAS). LI-3000 (Licor Inc., NE, USA) portable leaf area meter was used for measuring leaf area, leaf length, maximum 
width and the average width of each selected leaf. Leaves were carefully selected from the same position on three different plants to avoid differences in physiological age.

Growth attributes

Two plants per pot were randomly selected and marked during their seedling stage. Data on tiller number, leaf number, and plant height were collected from the marked plants on a weekly basis for five weeks starting when leaf nodes were visible in the sampled plants. Plant heights were recorded from the base of the plant to the uppermost collar on the main stem. The rate of increase in plant height per day was calculated. Tiller number was counted for each of the two plants and leaf numbers were counted in the main stem of the same plants.

\section{Growth Chamber experiment}

The growth chamber experiment was conducted in a controlled environment research laboratory (CERL) at Oklahoma State University. Four identical growth chambers each with 50 PVC pots $(15 \mathrm{~cm}$ in diameter and $35 \mathrm{~cm}$ in depth) were used for the study. The set of 100 Buster lines were thus split between two growth chambers. Fifty Buster lines were planted in each chamber, four seeds of one Buster line in each pot. An automated irrigation system was used to provide $0.3 \mathrm{~L}$ of Hoagland's nutrient solution to the plants each time, three times a day (8:00 AM, 1:00 PM and 6:00 PM), after germination. Pure sand was used as the growth medium. Plants in all chambers were grown at temperatures $\left(22 / 16^{\circ} \mathrm{C}\right.$ day/night) up to 65 days after sowing (DAS) and continued to grow at the same temperature in two chambers which were designated as controls. The temperature was raised to $32 / 26^{\circ} \mathrm{C}$ (day/night) in two of the chambers after 65 DAS to impose heat stress on one set of Buster lines. A gradual increase in temperature from night to day and vice-versa was achieved through temperature ramping. The photoperiod was adjusted to 14 hours light period and 10 hours dark period. Thus, one set of the 100 lines was under heat stress treatment, and the other set was grown under control conditions. Data on plant physiological parameters were collected from this experiment.

\section{Gas exchange parameters and fluorescence}

Parameters such as Pn, $\mathrm{g}_{\mathrm{s}}, \mathrm{E}, \mathrm{C}_{\mathrm{i}}$, ETR and Fv'/Fm' were determined on leaves between 9 AM to 1 PM using an infrared gas analyzer (IRGA) in an open photosynthesis system, LI-6400 XT (Licor Inc., NE, USA). The two youngest fully opened leaves from adjacent plants (similar leaf position) were used for the measurements in order to cover the $2 \mathrm{~cm}^{2}$ area of the leaf cuvette. The leaves were artificially irradiated at $1200 \mu \mathrm{mol} \cdot \mathrm{m}^{-2} \cdot \mathrm{s}^{-1}$ with a blue-red LED radiation source attached to the sensor head set. The temperature in the leaf cuvette was set in accordance with the daytime temperature of the treatment chambers. The leaf chamber reference $\mathrm{CO}_{2}$ was set to $400 \mu \mathrm{L} \cdot \mathrm{L}^{-1}$.

The efficiency of energy harvesting by photosystem II (PSII) was calculated by built-in algorithms in the LI-6400XT system using the equation:

$$
\mathrm{Fv}^{\prime} / \mathrm{Fm}^{\prime}=\left(\mathrm{Fm}^{\prime}-\mathrm{Fo}^{\prime}\right) / \mathrm{Fm}^{\prime}
$$


where,

Fo' $^{\prime}$ minimal fluorescence of a momentarily darkened leaf;

Fm' = maximum fluorescence during a saturating flash light;

$\mathrm{Fv}^{\prime}=$ variable fluorescence during a saturating flash light.

Instantaneous water use efficiency (IWUE) was calculated as the ratio of net photosynthesis $(\mathrm{Pn})$ to transpiration $(\mathrm{T})$.

The gas exchange parameters and fluorescence were measured three times: first before starting the heat stress treatment, second after three days of the treatment, and third a week after the treatment. The measurements taken after the introduction of heat stress are expressed as an average and compared to the average before heat stress treatment.

\section{Statistical analysis}

Data collected was analyzed using SAS Version 9.4 (SAS Institute, Cary, NC). The Analysis of Variance (ANOVA) was performed using PROC GLM to see if the Buster lines are statistically significant at $p=0.05$ probability level for the recorded parameters. PROC CORR was used to obtain correlation coefficients between the different parameters. Graphs were constructed using Sigma Plot.

Principal component analysis (PCA) was conducted using PROC PRINCOMP on the gas-exchange parameters data. The PCA was performed on the differences between values of the parameters in control and treatment conditions to identify the variables that were mainly causing the differences. A biplot, graphical representation of eigenvectors, also known as loadings, of the first two PC scores, was constructed using PROC PRINQUAL.

\section{Results}

\section{Greenhouse study}

Growth attributes (plant height, tiller number, and leaf number)

The average plant height ranged from $8.4 \mathrm{~cm}$ in line DH97 to $13.3 \mathrm{~cm}$ in DH14 and DH29. Significant differences $(P<0.05)$ were observed between Buster lines for the rate of increase in plant height and tiller number. The highest rate of increase in plant height was found in a parental line "Billings", and the lowest rate was observed in a Buster line "DH231" followed by another parental line "Duster". The number of tillers and rate of increase in tiller number were highest in Buster line "DH136" and lowest in "DH224".

The number of leaves on the main stem was not significantly different among the Buster lines. The final plant height is weakly negatively correlated to the rate of increase in leaf number (Table 1).

\section{Photosynthetic pigments}

Differences in concentrations were observed for different pigments among the Buster lines but were not statistically significant $(P>0.05)$. The $\mathrm{p}$-values for chlorophyll A, chlorophyll B, carotenoids and phenolic contents are $0.75,0.95$, 0.11 and 0.29 , respectively. Chlorophyll A:B ratio ranged from 1.8 in DH55 to 4.3 in DH54. The photosynthetic pigments positively correlated to each other at 
0.01 levels of significance (Table 1). Among those, chlorophyll A and B, and carotenoids showed a stronger correlation with each other.

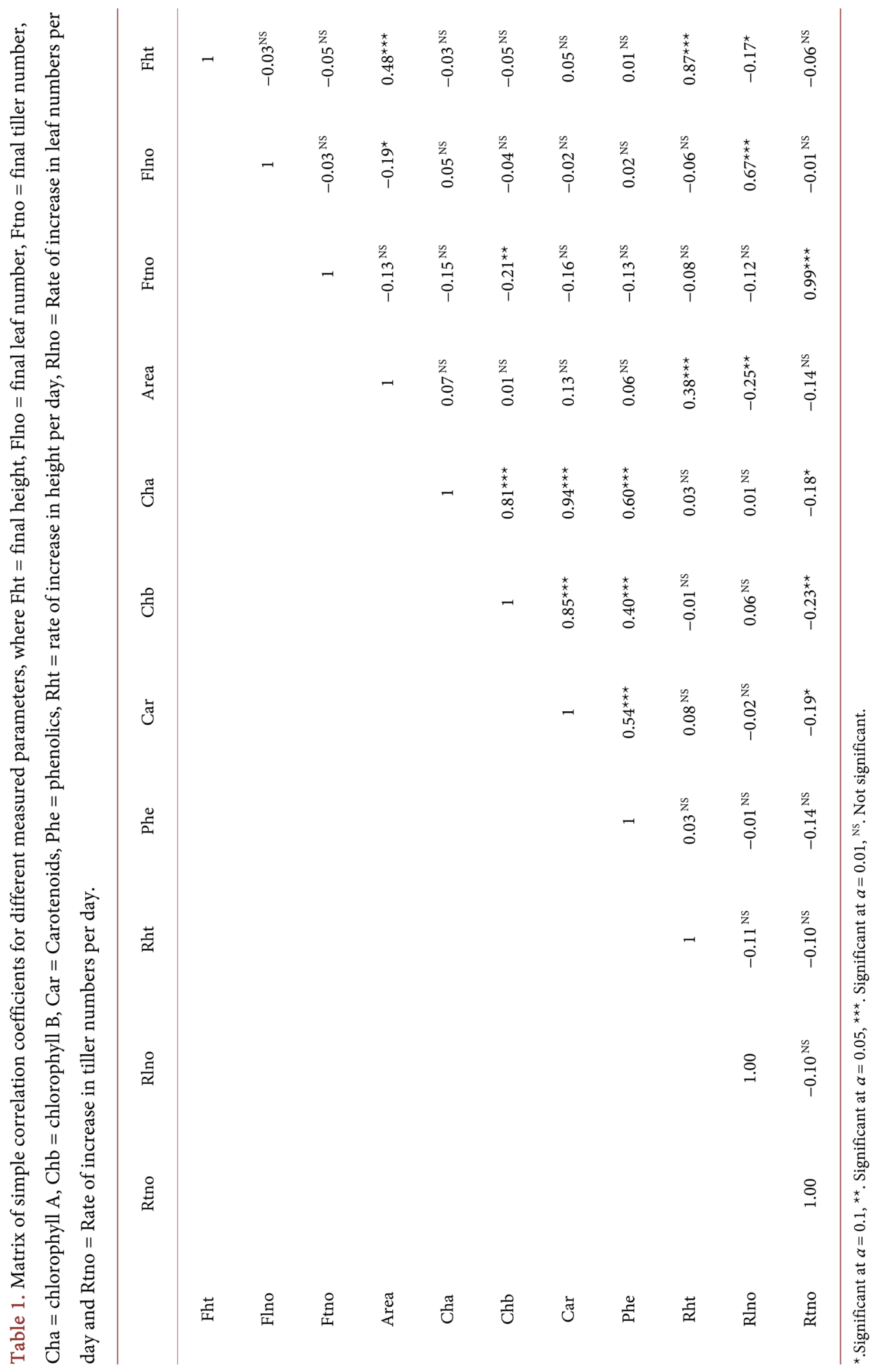


To depict the observed differences, the Buster lines are grouped for individual pigment components chlorophyll $\mathrm{A}$, chlorophyll $\mathrm{B}$, carotenoids and phenolic content based on mean \pm 1 and 2 standard deviations (Figure 1).

Leaf morphological attributes

Significant $(P<0.05)$ differences between Buster lines were observed in leaf area, leaf length and leaf width. The leaf area ranged from $20.94 \mathrm{~cm}^{2}$ in parental line "Duster" to $38.56 \mathrm{~cm}^{2}$ in Buster line "DH73" with an average of $28.85 \mathrm{~cm}^{2}$ and s.d. of $3.59 \mathrm{~cm}^{2}$ in the population. The Buster lines are grouped based on leaf area mean \pm 1 s.d. and mean \pm 2 s.d. (Figure 2 ). Leaf area was significantly positively correlated to the height attributes whereas it negatively correlated to leaf number attributes (Table 1).

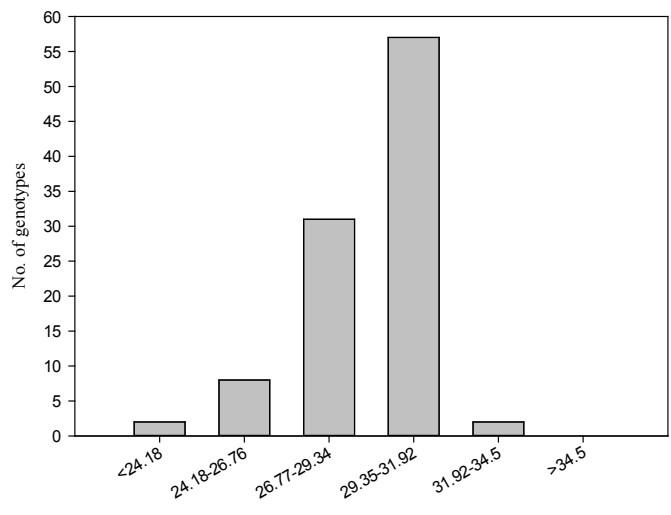

Chlorophyll A concentration $(\square \mathrm{g} / \mathrm{ml})$

(a)

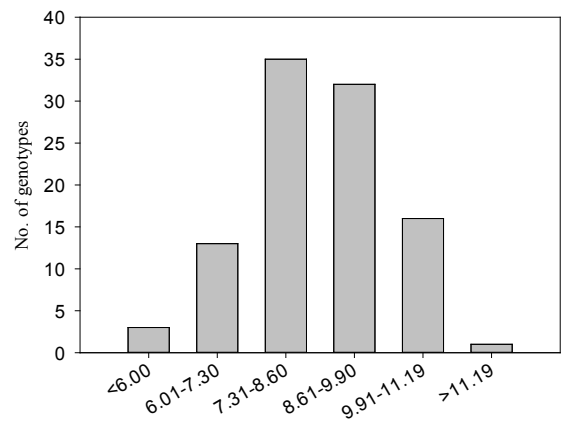

Chlorophyll B concentration $(\square \mathrm{g} / \mathrm{ml})$

(b)

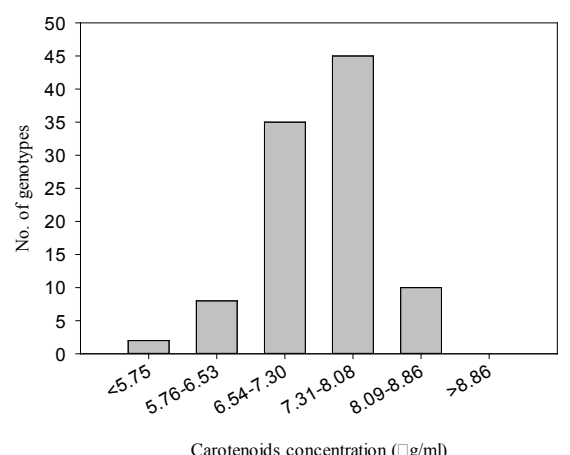

(c) 


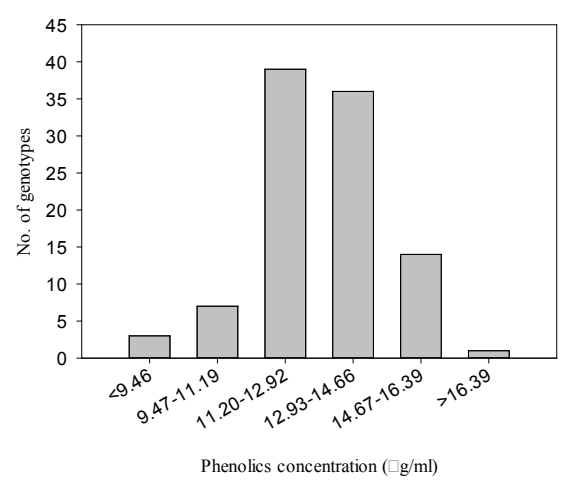

(d)

Figure 1. Number of Buster lines for each group of (a) Chlorophyll A, (b) Chlorophyll B, (c) Carotenoids, and (d) phenolic compounds concentrations $(\mu \mathrm{g} / \mathrm{ml})$ based on mean \pm s.d.

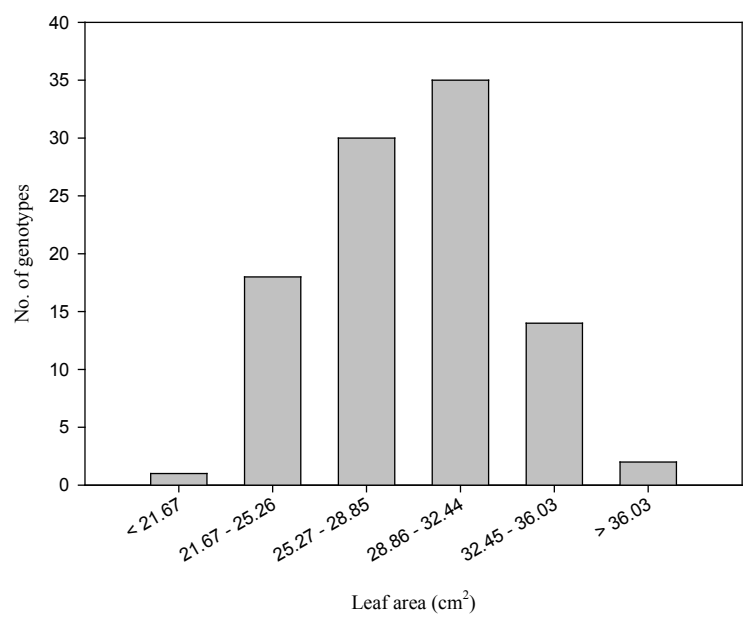

Figure 2. Number of Buster lines for each group of leaf area based on mean \pm s.d.

\section{Growth Chamber study}

\section{Gas exchange parameters and leaf fluorescence}

Before heat stress, the Buster lines were not statistically different for gas exchange and fluorescence parameters (data not shown). Whereas after heat stress, significant differences $(P<0.05)$ were observed between the genotypes in interaction with temperature for $\mathrm{Pn}, \mathrm{g}_{\mathrm{s}}, \mathrm{T}, \mathrm{Fv} / \mathrm{Fm}, \mathrm{C}_{\mathrm{i}}$ and IWUE with p-values of $0.0041,0.0095,0.0011,0.0166,0.0002$, and less than 0.0001 respectively (Table 2).

The $\mathrm{Pn}, \mathrm{g}_{\mathrm{s}}, \mathrm{T}$ and $\mathrm{C}_{\mathrm{i}}$ increased in the Buster lines in response to increased temperature. The parameters $\mathrm{Fv}^{\prime} / \mathrm{Fm}^{\prime}$ and ETR did not show consistent responses to the increase in temperature for the studied Buster lines. In response to the increase in temperature, the values for $\mathrm{Fv}^{\prime} / \mathrm{Fm}$ 'decreased in 58 lines and increased in 37 lines, whereas ETR increased in 78 lines and decreased in 17 lines.

Upon studying the relationship between the recorded parameters, the strongest correlation is observed between $\mathrm{g}_{\mathrm{s}}$ and $\mathrm{T}$ with a correlation coefficient of 0.97 . 
The variables $\mathrm{Pn}, \mathrm{g}_{\mathrm{s}}, \mathrm{E}$ and $\mathrm{C}_{\mathrm{i}}$ all were strongly positively correlated (correlation coefficients greater than 0.8 ) with each other (Table 3 ). The IWUE was negatively correlated to $\mathrm{Pn}, \mathrm{g}_{\mathrm{s}}, \mathrm{T}$, and $\mathrm{C}_{\mathrm{i}}$. The decrease in IWUE in response to heat stress ranged from $1.28 \mu \mathrm{mol} \mathrm{CO}_{2} / \mu \mathrm{mol} \mathrm{H}_{2} \mathrm{O}$ (DH263) to $8.45 \mu \mathrm{mol} \mathrm{CO}_{2} / \mu \mathrm{mol}$ $\mathrm{H}_{2} \mathrm{O}$ (DH102). The decrease was 2.6 and $3.4 \mu \mathrm{mol} \mathrm{CO}_{2} / \mu \mathrm{mol} \mathrm{H}_{2} \mathrm{O}$ for the parental lines "Duster" and "Billings" respectively. The electron transport rate was not correlated to any of the parameters and $\mathrm{Fv}^{\prime} / \mathrm{Fm}$ ' had a weak positive correlation with $\mathrm{Pn}$ and $\mathrm{C}_{\mathrm{i}}$.

From the results of PCA, it was observed that more than $80 \%$ of the variability was explained by the first two PC scores (Table 4). The biplot shows that $\mathrm{g}_{\mathrm{s}}$ and IWUE explain most of the variability in the first and second axis, respectively (Figure 3). The Buster lines in the upper right (first) quadrant have a comparatively small increase in $\mathrm{g}_{\mathrm{s}}, \mathrm{T}$ and $\mathrm{Pn}$ and the Buster lines in lower (third and fourth) quadrants are relatively less affected by heat stress as indicated by less difference in IWUE between control and treatment conditions.

Table 2. P-values for photosynthesis, stomatal conductance, transpiration, ETR, fluorescence, instantaneous WUE and intercellular $\mathrm{CO}_{2}$ showing significant differences for main factors (genotype and heat stress treatment) and their interaction.

\begin{tabular}{|c|c|c|c|}
\hline Parameter & Genotype & Treatment & Genotype ${ }^{\star}$ treatment \\
\hline Photosynthesis & $<0.0001^{\star \star \star}$ & $<0.0001^{\star * *}$ & $0.0041^{\star *}$ \\
\hline Stomatal conductance & $0.0048^{* *}$ & $<0.0001^{\star * *}$ & $0.0095^{\star *}$ \\
\hline Transpiration & $<0.0001^{\star * *}$ & $<0.0001^{\star * *}$ & $0.0011^{\star *}$ \\
\hline ETR & $0.5408^{\mathrm{NS}}$ & $0.8598^{\mathrm{NS}}$ & $0.5083^{\mathrm{NS}}$ \\
\hline Fluorescence & $0.0275^{\star}$ & $0.0536^{\mathrm{NS}}$ & $0.0166^{*}$ \\
\hline Instantaneous WUE & $<0.0001^{\star * *}$ & $<0.0001^{\star * *}$ & $<0.0001^{\star * *}$ \\
\hline Intercellular $\mathrm{CO}_{2}$ & $<0.0001^{\star * *}$ & $<0.0001^{\star * *}$ & $0.0002^{* * *}$ \\
\hline
\end{tabular}

* Significant at $\alpha=0.05,{ }^{* *}$ Significant at $\alpha=0.01,{ }^{* *}$ Significant at $\alpha=0.001,{ }^{\text {NS }}$ not significant.

Table 3. Matrix of Pearson correlation coefficients showing correlation between photosynthesis $(\mathrm{Pn})$, stomatal conductance $\left(\mathrm{g}_{\mathrm{s}}\right)$, transpiration $(\mathrm{E})$, intercellular $\mathrm{CO}_{2}\left(\mathrm{C}_{\mathrm{i}}\right)$, ETR, fluorescence $(\mathrm{Fv} / \mathrm{Fm})$ and instantaneous water use efficiency (IWUE).

\begin{tabular}{|c|c|c|c|c|c|c|c|}
\hline & Pn & $\mathrm{g}_{\mathrm{s}}$ & $\mathrm{E}$ & IWUE & ETR & $\mathrm{Fv}^{\prime} / \mathrm{Fm}^{\prime}$ & $\mathrm{C}_{\mathrm{i}}$ \\
\hline Pn & 1 & $0.89^{* * *}$ & $0.84^{* * *}$ & $-0.58^{\star * *}$ & $0.06^{\mathrm{NS}}$ & $0.21^{\star * *}$ & $0.71^{\star * *}$ \\
\hline$g_{s}$ & 0.89 & 1 & $0.97^{\star * *}$ & $-0.78^{\star * *}$ & $0.03^{\mathrm{NS}}$ & $0.09^{\mathrm{NS}}$ & $0.88^{\star * \star}$ \\
\hline $\mathrm{E}$ & 0.84 & 0.97 & 1 & $-0.85^{\star \star *}$ & $0.03^{\mathrm{NS}}$ & 0.01 NS & $0.85^{\star * \star}$ \\
\hline IWUE & -0.58 & -0.78 & -0.85 & 1 & $0.00^{\mathrm{NS}}$ & $-0.03^{\mathrm{NS}}$ & $-0.86^{\star * *}$ \\
\hline ETR & 0.06 & 0.03 & 0.03 & 0.00 & 1 & $0.00^{\mathrm{NS}}$ & $0.01 \mathrm{NS}$ \\
\hline $\mathrm{Fv}^{\prime} / \mathrm{Fm}^{\prime}$ & 0.21 & 0.09 & 0.01 & -0.03 & 0.00 & 1 & $0.16^{* *}$ \\
\hline $\mathrm{C}_{\mathrm{i}}$ & 0.71 & 0.88 & 0.85 & -0.86 & 0.01 & 0.16 & 1 \\
\hline
\end{tabular}

${ }^{\star}$ Significant at $\alpha=0.05{ }^{\star *}$ Significant at $\alpha=0.01{ }^{\star *}$ Significant at $\alpha=0.001,{ }^{\text {NS }}$ not significant. 
Table 4. Eigenvectors (loadings) of the principal components and proportional and cumulative variance explained by the principal components.

\begin{tabular}{cccccccc}
\hline & Prin1 & Prin2 & Prin3 & Prin4 & Prin5 & Prin6 & Prin7 \\
\hline Photosynthesis & 0.42 & 0.36 & 0.06 & -0.13 & -0.27 & 0.65 & -0.42 \\
Stomatal conductance & 0.47 & 0.06 & -0.09 & 0.12 & 0.44 & -0.49 & -0.56 \\
ETR & 0.30 & 0.57 & -0.10 & 0.04 & -0.48 & -0.46 & 0.37 \\
Transpiration & 0.46 & 0.00 & -0.17 & -0.39 & 0.51 & 0.21 & 0.55 \\
IWUE & -0.22 & 0.59 & 0.37 & 0.45 & 0.46 & 0.16 & 0.13 \\
Fluorescence & 0.31 & -0.27 & 0.88 & -0.08 & -0.11 & -0.13 & 0.10 \\
Intercellular CO 2 & 0.38 & -0.35 & -0.18 & 0.78 & -0.11 & 0.20 & 0.21 \\
Proportional variance & 0.57 & 0.24 & 0.09 & 0.05 & 0.03 & 0.01 & 0.01 \\
Cumulative variance & 0.57 & 0.81 & 0.90 & 0.95 & 0.98 & 0.99 & 1.00 \\
\hline
\end{tabular}

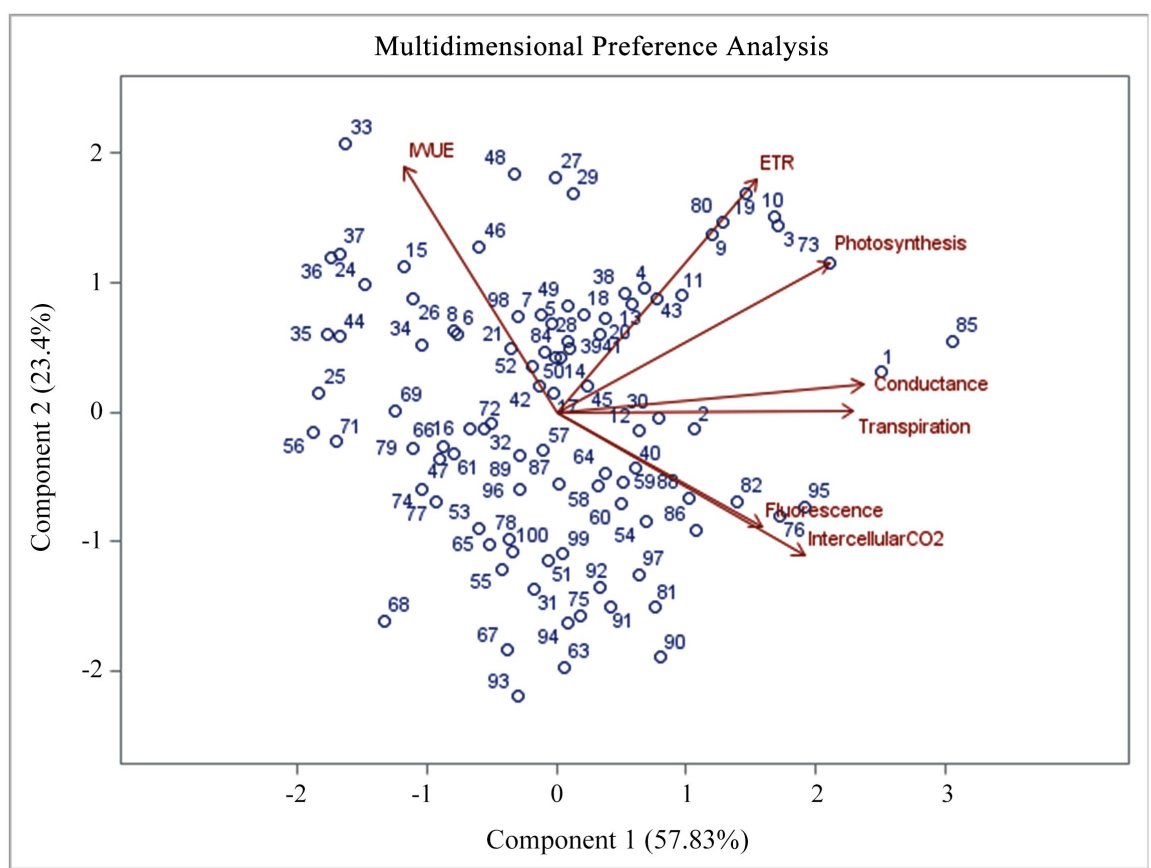

Figure 3. Biplot of the eigenvectors of first two principal component scores. The genotype numbers correspond to genotype numbers in Table 4.

\section{Discussion}

\section{Greenhouse study}

Growth attributes (plant height, tiller number, and leaf number)

The wide range in average plant height within the population indicates that the population is well segregated for plant height. "Duster" and "Billings" are both categorized as intermediate semi-dwarfs but differ in plant heights; "Duster" $(71 \mathrm{~cm})$ [46] and "Billings" $(73 \mathrm{~cm})$ [47]. Although these plant heights represent the heights from ground level to spike tip, these differences were visible during the vegetative plant growth stages in our study. 
A higher number of tillers contribute towards higher harvest index in normal conditions but a reduced number of tillers are desirable under water deficit [8]. The differences in tiller numbers, in this case, can be explained by probable segregation of genes in the population for tiller number because the parental line "Duster" is known to have a high tiller number while "Billings" lacks this attribute. Duster and Billings showed wide pattern differences in reproductive development, yet all known genes for reproductive development were identical between them (B. Carver, personal communication). The number of tillers observed is an indicator of the tillering capacity of a genotype because the plants were putting new tillers for a long time since there was no vernalization imposed for the plants to start the reproductive phase.

The parental lines "Duster" and "Billings" do not have reported differences for the leaf number or rates of increase in leaf number. This might be a result of a limited time period in which the data was collected i.e. five weeks. Unlike tiller number and plant height, which gain measurable increments in a short time period, it requires a long time for a leaf to be fully developed and thus the data collection duration might not have been sufficient enough to reflect the differences in leaf number among the genotypes if any.

\section{Photosynthetic pigments}

A study done by [48] found no significant differences for chlorophyll content among genotypes when the first spikelet of the inflorescence was visible, close to the vegetative stage, but differences were recorded for later growth stages [48]. Studies have shown differences in chlorophyll content in different wheat cultivars and under different stress conditions [49] [50]. There is very limited information on carotenoids analysis on leaves, especially in the context of wheat where studies are concentrated towards grain carotenoids content in durum wheat. Studies show differences in carotenoids content in leaves for different genotypes and stress combinations in crops like soybeans [51] and tomatoes [52]. Similarly, phenolic content in leaves and their role in scavenging ROS have been studied under various abiotic stress conditions like drought and salinity but not yet studied for non-stressed conditions. Differences in phenolic compounds concentration have been found in response to stress at various growth stages where differences were mostly expressed at reproductive stages of plant growth [53]. The heterogeneity of the Buster lines is deemed to be not enough to reflect differences in the photosynthetic pigments to a significant effect.

\section{Leaf morphological attributes}

Most of the Buster lines demonstrated greater leaf area than the parental lines because of the segregation of genes in the DH population. In a study by [54], significant differences were observed in leaf areas and a weak negative correlation between leaf area and water use efficiency was reported.

\section{Correlation between parameters}

No such correlations have been studied specifically, but studies have been done with the plant height and leaf area as the selection criteria. Our results showing the plant height and leaf area positively correlated to each other pro- 
vides an opportunity to select Buster lines with shorter plant height and lower leaf area at the same time, which are the desirable characteristics of wheat in drought-prone areas.

\section{Growth Chamber study}

\section{Gas exchange parameters and leaf fluorescence}

In the past, genotypic differences for gas exchange parameters among different wheat varieties are commonly observed [23] [55] [56]. Our results indicate that the differences in Buster lines are prominently expressed under stress than in normal conditions.

Since all gas exchange parameters are directly related to stomatal opening, their increase under heat stress is directly related to increased stomatal apertures. The stomatal conductance is not limited by the high temperature unless water stress is associated with it [57]. The higher stomatal conductance under high temperatures also explains the transpirational cooling mechanism of plants in response to high temperatures. Higher transpiration rates in higher temperatures allow more water vapor to exit the leaves ultimately having a cooling effect. On the other hand, increased stomatal openings allow more $\mathrm{CO}_{2}$ to enter the leaves, which increases photosynthesis. Furthermore, an increase in enzymatic activity of Rubisco with an increase in temperature also influences photosynthesis in high temperatures and sufficient water conditions [22]. A review done by [58] suggests that the yields of cotton and wheat are directly correlated to the stomatal conductance under supra optimal temperatures when there's no influence of other stresses like drought and vapor pressure deficit. They also concluded that an increase in stomatal conductance is an avoiding type of resistance in response to the high temperatures but the water use efficiency is decreased with the increase in temperature because of wasteful water use, which is in accordance with the results of this experiment. However, in the literature, the gas exchange parameters are found to have no correlation with the yield parameters [59]. This study gives us an idea of the potential performance of Buster lines but cannot conclude on the plant responses to naturally occurring heat stress that is associated with water stress most of the time.

The correlation of $\mathrm{g}_{\mathrm{s}}$ with $\mathrm{Pn}$ and $\mathrm{T}$ is expected because the rate of flow $\mathrm{Cf}_{2}$ and water vapor in and out of the leaves is controlled by the stomatal aperture. However, the negative correlation of IWUE with the gas exchange parameters suggests that water is not being efficiently used and photosynthesis is increased at a very high cost of water.

A study done by [23] under drought reported no correlation between the gas exchange parameters and IWUE.

\section{Conclusion}

The Buster lines were significantly different in the morphological traits such as plant height, tiller number, and leaf area under heat stress. The tiller number recorded in this study is an indicator of the potential tillering capacity of the ge- 
notype. The genotypic differences based on gas exchange parameters were discernible only under heat stress. The variables $g_{s}$ and IWUE explained most of the differences between the treatments. The IWUE decreased in response to heat stress in all Buster lines at different rates, whereas the values for gas exchange parameters increased under heat stress compared to controlled conditions. Thus, the Buster lines can potentially be selected for further breeding programs based on their morphological differences and physiological response to stress.

\section{Acknowledgements}

Authors would like to acknowledge support from Oklahoma Agricultural Experiment Station, Hatch project no. 2969 and Oklahoma Wheat Commission for this study.

\section{Conflicts of Interest}

The authors declare no conflicts of interest regarding the publication of this paper.

\section{References}

[1] Stainforth, D.A., Aina, T., Christensen, C., Collins, M., Faull, N., Frame, D.J., Kettleborough, J.A., Knight, S., Martin, A., Murphy, J.M., Piani, C., Sexton, D., Smith, L.A., Spicer, R.A., Thorpe, A.J. and Allen, M.R. (2005) Uncertainty in Predictions of the Climate Response to Rising Levels of Greenhouse Gases. Nature, 433, 403-406. https://doi.org/10.1038/nature03301

[2] Gourdji, S.M., Sibley, A.M. and Lobell, D.B. (2013) Global Crop Exposure to Critical High Temperatures in the Reproductive Period: Historical Trends and Future Projections. Environmental Research Letters, 8, Article ID: 024041. https://doi.org/10.1088/1748-9326/8/2/024041

[3] Rebetzke, G.J., Rattey, A.R., Farquhar, G.D., Richards, R.A. and Condon, A.G. (2013) Genomic Regions for Canopy Temperature and Their Genetic Association with Stomatal Conductance and Grain Yield in Wheat. Functional Plant Biology, 40, 14-33. https://doi.org/10.1071/FP12184

[4] Rosyara, U.R., Vromman, D. and Duveiller, E. (2008) Canopy Temperature Depression as an Indication of Correlative Measure of Spot Blotch Resistance and Heat Stress Tolerance in Spring Wheat. Journal of Plant Pathology, 90, 103-107.

[5] Yang, J., Sears, R.G., Gill, B.S. and Paulsen, G.M. (2002) Genotypic Differences in Utilization of Assimilate Sources during Maturation of Wheat under Chronic Heat and Heat Shock Stresses-Utilization of Assimilate Sources by Wheat under Heat Stresses. Euphytica, 125, 179-188. https://doi.org/10.1023/A:1015882825112

[6] Austin, R.B., Bingham, J., Blackwell, R.D., Evans, L.T., Ford, M.A., Morgan, C.L. and Taylor, M. (1980) Genetic Improvements in Winter Wheat Yields Since 1900 and Associated Physiological Changes. The Journal of Agricultural Science, 94, 675-689. https://doi.org/10.1017/S0021859600028665

[7] Ilker, E., Tonk, F.A., Tosun, M. and Tatar, O. (2013) Effects of Direct Selection Process for Plant Height on Some Yield Components in Common Wheat (Triticum aestivum) Genotypes. International Journal of Agriculture and Biology, 15, 795-797.

[8] Duggan, B.L., Richards, R.A., Van, Herwaarden A.F. and Fettell, N.A. (2005) Agro- 
nomic Evaluation of a Tiller Inhibition Gene (Tin) in Wheat. I. Effect on Yield, Yield Components, and Grain Protein. Crop and Pasture Science, 56, 169-178. https://doi.org/10.1071/AR04152

[9] Righetti, T.L., Vasconcelos, C., Sandrock, D.R., Ortega-Farias, S., Moreno, Y. and Meza, F.J. (2007) Assessments of $\mathrm{CO}_{2}$ Assimilation on a Per-Leaf-Area Basis Are Related to Total Leaf Area. Journal of the American Society for Horticultural Science, 132, 230-238. https://doi.org/10.21273/JASHS.132.2.230

[10] Ali, M.A., Zulkiffal, M., Anwar, J., Hussain, M., Farooq, J. and Khan, S.H. (2015) Morpho-Physiological Diversity in Advanced Lines of Bread Wheat under Drought Conditions at Post-Anthesis Stage. Journal of Animal and Plant Sciences, 25, 431-441.

[11] Balota, M., Payne, W.A., Evett, S.R. and Peters, T.R. (2008) Morphological and Physiological Traits Associated with Canopy Temperature Depression in Three Closely Related Wheat Lines. Crop Science, 48, 1897-1910. https://doi.org/10.2135/cropsci2007.06.0317

[12] Ihsan, M.Z., El-Nakhlawy, F.S., Ismail, S.M., Fahad, S. and Daur, I. (2016) Wheat Phenological Development and Growth Studies as Affected by Drought and Late Season High Temperature Stress under Arid Environment. Frontiers in Plant Science, 7, Article 795. https://doi.org/10.3389/fpls.2016.00795

[13] Naruoka, Y., Talbert, L.E., Lanning, S.P., Blake, N.K., Martin, J.M. and Sherman, J.D. (2011) Identification of Quantitative Trait Loci for Productive Tiller Number and Its Relationship to Agronomic Traits in Spring Wheat. Theoretical and Applied Genetics, 123, Article No. 1043. https://doi.org/10.1007/s00122-011-1646-0

[14] Bos, H.J. and Neuteboom, J.H. (1998) Morphological Analysis of Leaf and Tiller Number Dynamics of Wheat (Triticum aestivum L.): Responses to Temperature and Light Intensity. Annals of Botany, 81, 131-139.

https://doi.org/10.1006/anbo.1997.0531

[15] Rybka, K. and Nita, Z. (2015) Physiological Requirements for Wheat Ideotypes in Response to Drought Threat. Acta Physiologiae Plantarum, 37, Article No. 97. https://doi.org/10.1007/s11738-015-1844-5

[16] Bhagsari, A.S. and Brown, R.H. (1986) Leaf Photosynthesis and Its Correlation with Leaf Area. Crop Science, 26, 127-132. https://doi.org/10.2135/cropsci1986.0011183X002600010030x

[17] Oritani, T., Enbutsu, T. and Yoshida, R. (1979) Studies on Nitrogen-Metabolism Crop Plants: XVI. Changes in Photosynthesis and Nitrogen-Metabolism in Relation to Leaf Area Growth of Several Rice Varieties. Japanese Journal of Crop Science, 48, 10-16. https://doi.org/10.1626/jcs.48.10

[18] Reynolds, M., Foulkes, M.J., Slafer, G.A., Berry, P., Parry, M.A., Snape, J.W. and Angus, W.J. (2009) Raising Yield Potential in Wheat. Journal of Experimental Botany, 60, 1899-1918. https://doi.org/10.1093/jxb/erp016

[19] Richards, R.A. (2000) Selectable Traits to Increase Crop Photosynthesis and Yield of Grain Crops. Journal of Experimental Botany, 51, 447-458. https://doi.org/10.1093/jexbot/51.suppl_1.447

[20] Zheng, T.C., Zhang, X.K., Yin, G.H., Wang, L.N., Han, Y.L., Chen, L., Huang, F., Tang, J.W., Xia, X.C. and He, Z.H. (2011) Genetic Gains in Grain Yield, Net Photosynthesis and Stomatal Conductance Achieved in Henan Province of China between 1981 and 2008. Field Crops Research, 122, 225-233. https://doi.org/10.1016/j.fcr.2011.03.015

[21] Kakani, V.G., Surabhi, G.K. and Reddy, K.R. (2008) Photosynthesis and Fluores- 
cence Responses of $\mathrm{C}_{4}$ Plant Andropogon gerardii Acclimated to Temperature and Carbon Dioxide. Photosynthetica, 46, 420-430.

[22] Salvucci, M.E. and Crafts-Brandner, S.J. (2004) Inhibition of Photosynthesis by Heat Stress: The Activation State of Rubisco as a Limiting Factor in Photosynthesis. Physiologia Plantarum, 120, 179-186. https://doi.org/10.1111/j.0031-9317.2004.0173.x

[23] Xue, Q.W., Soundararajan, M., Weiss, A., Arkebauer, T.J. and Baenziger, P.S. (2002) Genotypic Variation of Gas Exchange Parameters and Carbon Isotope Discrimination in Winter Wheat. Journal of Plant Physiology, 159, 891-898. https://doi.org/10.1078/0176-1617-00780

[24] Long, S.P., Zhu, X.G., Naidu, S.L. and Ort, D.R. (2006) Can Improvement in Photosynthesis Increase Crop Yields? Plant Cell and Environment, 29, 315-330. https://doi.org/10.1111/j.1365-3040.2005.01493.x

[25] Sikder, S., Foulkes, J., West, H., De Silva, J., Gaju, O., Greenland, A. and Howell, P. (2015) Evaluation of Photosynthetic Potential of Wheat Genotypes under Drought Condition. Photosynthetica, 53, 47-54. https://doi.org/10.1007/s11099-015-0082-9

[26] Fischer, R.A., Rees, D., Sayre, K.D., Lu, Z.M., Condon, A.G. and Saavedra, A.L. (1998) Wheat Yield Progress Associated with Higher Stomatal Conductance and Photosynthetic Rate, and Cooler Canopies. Crop Science, 38, 1467-1475. https://doi.org/10.2135/cropsci1998.0011183X003800060011x

[27] Dobrowski, S.Z., Pushnik, J.C., Zarco-Tejada, P.J. and Ustin, S.L. (2005) Simple Reflectance Indices Track Heat and Water Stress-Induced Changes in Steady-State Chlorophyll Fluorescence at the Canopy Scale. Remote Sensing of Environment, 97, 403-414. https://doi.org/10.1016/j.rse.2005.05.006

[28] Maxwell, K. and Johnson, G.N. (2000) Chlorophyll Fluorescence-A Practical Guide. Journal of Experimental Botany, 51, 659-668. https://doi.org/10.1093/jxb/51.345.659

[29] Krause, G.H. and Weis, E. (1991) Chlorophyll Fluorescence and Photosynthesis: The Basics. Annual Review of Plant Biology, 42, 313-349. https://doi.org/10.1146/annurev.pp.42.060191.001525

[30] Jiang, Q., Roche, D., Monaco, T.A. and Durham, S. (2006) Gas Exchange, Chlorophyll Fluorescence Parameters and Carbon Isotope Discrimination of 14 Barley Genetic Lines in Response to Salinity. Field Crops Research, 96, 269-278. https://doi.org/10.1016/j.fcr.2005.07.010

[31] Sharma, D.K. Andersen, S.B., Ottosen, C.O. and Rosenqvist, E. (2012) Phenotyping of Wheat Cultivars for Heat Tolerance Using Chlorophyll $\alpha$ Fluorescence. Functional Plant Biology, 39, 936-947. https://doi.org/10.1071/FP12100

[32] Zhao, H.J. and Zou, Q. (2002) Protective Effects of Exogenous Antioxidants and Phenolic Compounds on Photosynthesis of Wheat Leaves under High Irradiance and Oxidative Stress. Photosynthetica, 40, 523-527. https://doi.org/10.1023/A:1024339716382

[33] Asada, K. (1996) Radical Production and Scavenging in the Chloroplasts. In: Baker N.R., Ed., Photosynthesis and the Environment. Advances in Photosynthesis and Respiration, Springer, Dordrecht, 123-150. https://doi.org/10.1007/0-306-48135-9_5

[34] Richter, M., Rühle, W. and Wild, A. (1990) Studies on the Mechanism of Photosystem II Photoinhibition II. The Involvement of Toxic Oxygen Species. Photosynthesis Research, 24, 237-243. https://doi.org/10.1007/BF00032311

[35] Bowler, C., Montagu, M. and Inze, D. (1992) Superoxide Dismutase and Stress Tolerance. Annual Review of Plant Biology, 43, 83-116. 
https://doi.org/10.1146/annurev.pp.43.060192.000503

[36] Salah, N., Miller, N.J., Paganga, G., Tijburg, L., Bolwell, G.P. and Riceevans, C. (1995) Polyphenolic Flavanols as Scavengers of Aqueous Phase Radicals and as Chain-Breaking Antioxidants. Archives of Biochemistry and Biophysics, 322, 339-346. https://doi.org/10.1006/abbi.1995.1473

[37] Hatamnia, A.A., Rostamzad, A., Hosseini, M., Abbaspour, N., Darvishzadeh, R. Malekzadeh, P. and Aminzadeh, B.M. (2016) Antioxidant Capacity and Phenolic Composition of Leaves from 10 Bene (Pistacia atlantica subsp. kurdica) Genotypes. Natural Product Research, 30, 600-604. https://doi.org/10.1080/14786419.2015.1028060

[38] Hura, T., Hura, K. and Grzesiak, S. (2009) Leaf Dehydration Induces Different Content of Phenolics and Ferulic Acid in Drought-Resistant and -Sensitive Genotypes of Spring Triticale. Zeitschrift für Naturforschung Section C, 64, 85-95. https://doi.org/10.1515/znc-2009-1-215

[39] Cogdell, R.J. (1985) Carotenoids in Photosynthesis. Pure and Applied Chemistry, 57, 723-728. https://doi.org/10.1351/pac198557050723

[40] Damjanovic, A., Ritz, T. and Schulten, K. (1999) The Role of Carotenoids in Photosynthesis. Biophysical Journal, 76, A239-A239.

[41] Domonkos, I., Kis, M., Gombos, Z. and Ughy, B. (2013) Carotenoids, Versatile Components of Oxygenic Photosynthesis. Progress in Lipid Research, 52, 539-561. https://doi.org/10.1016/j.plipres.2013.07.001

[42] Burkhardt, S. and Bohm, V. (2007) Development of a New Method for the Complete Extraction of Carotenoids from Cereals with Special Reference to Durum Wheat (Triticum durum Desf.). Journal of Agricultural and Food Chemistry, 55, 8295-8301. https://doi.org/10.1021/jf0712853

[43] Frank, H.A. and Brudvig, G.W. (2004) Redox Functions of Carotenoids in Photosynthesis. Biochemistry, 43, 8607-8615. https://doi.org/10.1021/bi0492096

[44] Lichtenthaler, H.K. (1987) Chlorophylls and Carotenoids: Pigments of Photosynthetic Biomembranes. Methods in Enzymology, 148, 350-382. https://doi.org/10.1016/0076-6879(87)48036-1

[45] Kakani, V.G. Reddy, K.R., Zhao, D. and Gao, W. (2004) Senescence and Hyperspectral Reflectance of Cotton Leaves Exposed to Ultraviolet-B Radiation and Carbon Dioxide. Physiologia Plantarum, 121, 250-257. https://doi.org/10.1111/j.0031-9317.2004.00314.x

[46] Edwards, J.T., Hunger, R.M., Smith, E.L., Horn, G.W., Chen, M.S., Yan, L., Bai, G., Bowden, R.L., Klatt, A.R., Rayas-Duarte, P., Osburn, R.D., Giles, K.L., Kolmer, J.A., Jin, Y., Porter, D.R., Seabourn, B.W., Bayles, M.B. and Carver, B.F. (2012) “Duster" Wheat: A Durable, Dual-Purpose Cultivar Adapted to the Southern Great Plains of the USA. Journal of Plant Registrations, 6, 37-48.

https://doi.org/10.3198/jpr2011.04.0195crc

[47] Hunger, R.M., Edwards, J.T., Bowden, R.L., Yan, L.L., Rayas-Duarte, P., Bai, G.H., Bowden, R.L., Klatt, A.R., Rayas-Duarte, P., Osburn, R.D., Giles, K.L., Kolmer, J.A., Jin, Y., Porter, D.R., Seabourn, B.W., Bayles, M.B. and Carver, B.F. (2014) "Billings" Wheat Combines Early Maturity, Disease Resistance, and Desirable Grain Quality for the Southern Great Plains, USA. Journal of Plant Registrations, 8, 22-31. https://doi.org/10.3198/jpr2012.11.0053crc

[48] Abdipur, M., Ramezani, H.R., Bavei, V. and Talaee, S. (2013) Effectiveness of Canopy Temperature and Chlorophyll Content Measurements at Different Plant Growth Stages for Screening of Drought Tolerant Wheat Genotypes. Ameri- 
can-Eurasian Journal of Agricultural and Environmental Sciences, 13, 1325-1338.

[49] Akhkha, A., Boutraa, T. and Alhejely, A. (2011) The Rates of Photosynthesis, Chlorophyll Content, Dark Respiration, Proline and Abscicic Acid (Aba) in Wheat (Triticum durum) under Water Deficit Conditions. International Journal of Agriculture and Biology, 13, 215-221.

[50] Hamblin, J., Stefanova, K. and Angessa, T.T. (2014) Variation in Chlorophyll Content Per Unit Leaf Area in Spring Wheat and Implications for Selection in Segregating Material. PLoS ONE, 9, e92529. https://doi.org/10.1371/journal.pone.0092529

[51] Dhanapal, A.P., Ray, J.D., Singh, S.K., Hoyos-Villegas, V., Smith, J.R., Purcell, L.C., King, C.A. and Fritschi, F.B. (2015) Association Mapping of Total Carotenoids in Diverse Soybean Genotypes Based on Leaf Extracts and High-Throughput Canopy Spectral Reflectance Measurements. PLoS ONE, 10, e0137213. https://doi.org/10.1371/journal.pone.0137213

[52] Barickman, T.C., Kopsell, D.A. and Sams, C.E. (2014) Abscisic Acid increases Carotenoid and Chlorophyll Concentrations in Leaves and Fruit of Two Tomato Genotypes. Journal of the American Society for Horticultural Science, 139, 261-266. https://doi.org/10.21273/JASHS.139.3.261

[53] Ashraf, M.A., Ashraf, M. and Ali, Q. (2010) Response of Two Genetically Diverse Wheat Cultivars to Salt Stress at Different Growth Stages: Leaf Lipid Peroxidation and Phenolic Contents, Pakistan Journal of Botany, 42, 559-565.

[54] Morgan, J.A. and Lecain, D.R. (1991) Leaf Gas Exchange and Related Leaf Traits among 15 Winter Wheat Genotypes. Crop Science, 31, 443-448. https://doi.org/10.2135/cropsci1991.0011183X003100020044x

[55] Wu, X.L. and Bao, W.K. (2011) Leaf Growth, Gas Exchange and Chlorophyll Fluorescence Parameters in Response to Different Water Deficits in Wheat Cultivars. Plant Production Science, 14, 254-259. https://doi.org/10.1626/pps.14.254

[56] Ritchie, S.W., Nguyen, H.T. and Holaday, A.S. (1988) Leaf Water Content and Gas Exchange Parameters of Two Wheat Genotypes Differing in Drought Resistance. Crop Science, 30, 105-111. https://doi.org/10.2135/cropsci1990.0011183X003000010025x

[57] Baker, N.R. (2006) Photosynthesis and the Environment Vol. 5. Springer Science and Business Media, Berlin.

[58] Lu, Z., Percy, R.G., Qualset, C.O. and Zeiger, E. (1998) Stomatal Conductance Predicts Yields in Irrigated Pima Cotton and Bread Wheat Grown at High Temperatures. Journal of Experimental Botany, 49, 453-460. https://doi.org/10.1093/jxb/49.Special_Issue.453

[59] Feng, B., Liu, P., Li, G., Dong, S.T., Wang, F.H., Kong, L.A. and Zhang, J.W. (2014) Effect of Heat Stress on the Photosynthetic Characteristics in Flag Leaves at the Grain-Filling Stage of Different Heat-Resistant Winter Wheat Varieties. Journal of Agronomy and Crop Science, 200, 143-155. https://doi.org/10.1111/jac.12045 


\section{Abbreviations}

DH, Double Haploid; Pn, net photosynthesis; $\mathrm{g}_{\mathrm{s}}$, stomatal conductance; $\mathrm{C}_{\mathrm{i}}$, internal $\mathrm{CO}_{2}$ concentration; $\mathrm{T}$, transpiration; IWUE, instantaneous water use efficiency; ETR, electron transport rate; Fv'/Fm', Photosystem II efficiency; IRGA, infrared gas analyzer; CERL, controlled environment research laboratory; $\mu \mathrm{L} \cdot \mathrm{L}^{-1}$, microliter per liter; $\mu \mathrm{mol} \cdot \mathrm{m}^{-2} \cdot \mathrm{s}^{-1}$, micro mole per meter squared per second; ROS, reactive oxygen species; OSUWIT, Oklahoma State University Wheat Improvement Team; DMSO, Dimethyl Sulfoxide. 